\title{
The Health Behaviour of Black Hypertensive Patients at a Chronic Diseases Clinic IN A DEPRESSED SOCIO-ECONOMIC AREA of Johannesburg, South AFricA.
}

\begin{abstract}
A sample of hypertensive patients and the health care practitioners at an urban community health clinic were studied to identify their health status and behaviours. Barriers to compliance with health advice were also inves-

STEWART A V, EALES C J, SHEPARD K analysis of patients' records. Themes were generated from the coded data. The data revealed that the patients'compliance was poor (66\% attendance at the clinic), the mean blood pressure level was 157/99 and they were often symptomatic. Patients' understanding of hypertension was fragmented and they did not see it as a silent, chronic disease. They were beset by financial and family worries and stresses. The staff found that it was increasingly difficult to educate the patients as the numbers of patients at the clinic were increasing.
\end{abstract}

\section{KEYWORDS: HEALTH BEHAVIOUR, COMPLIANCE, UNDERSTANDING, BARRIERS}

\section{INTRODUCTION}

Patients' adherence to medical regimens and life-style modification is central to the management of most chronic disease. These patients are the ones who, on a daily basis, have to modify their health behaviour in such a way that they can manage their disease and cope with their daily lives. How well patients are able to manage their disease is dependent on how severe they see the disease is and whether they see the benefits of life - style modification as being worth the effort they will have to make to achieve these changes. Making this effort is dependent on a variety of psycho-social factors. (Janz and Becker 1984)
Two paradigms of patient education have been described. (Bartlett, 1982). The first is based on a teaching approach and the second on a behavioural diagnosis. Many questions are continually being raised about the effectiveness of patient education. Studies have shown that raising knowledge levels does not necessarily mean that there will be a behavioural change (Haynes, 1976; Morisky et al, 1982). This is particularly so in the management of a disease such as hypertension which, because of it's very nature, is fraught with difficulties (Caldwell et al, 1983; Sluijs, 1991). The second is based on a behavioural diagnosis which is the

FIGURE 1: FACTORS WHICH INFLUENCE HEALTH STATUS. (Barleft 1982)

These factors which influence one another will also influence a patient's health behaviour and his health status.

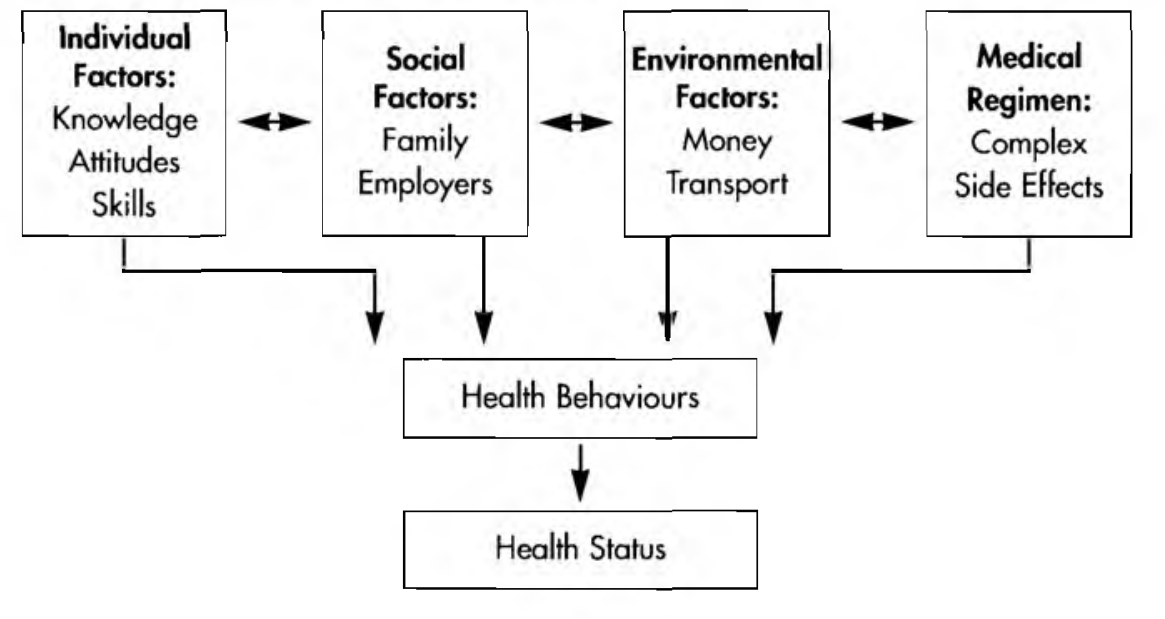

"assessment of influences on the desired patient behaviour" ( Bartlett, 1982). The behavioural diagnosis considers a variety of factors which either promote or discourage patients' adherence to health regimens (Bartlett 1982).

Various authors (Green,1978; Jenkins, 1979) described classifications of behaviour which influence patients' adherence. Green (1978) suggested a framework which incorporates a wide range of factors which may influence behaviour. He describes these as predisposing factors (knowledge, attitude, values, perceptions and norms); reinforcing factors (attitudes and behaviours of health personnel, family, peers, teachers and employers) and enabling factors (availability of resources, access, referral, designated skills and government health policy).

Bartlett (1982) argues that these classification systems although representing a major step forwards in patient education have a number of shortcomings namely, difficult terminology, difficulty in following complicated medical regimens and combining social and environmental factors into one category.

He suggests a much simpler classification as follows: (see Figure 1)

CORRESPONDENCE:

Mrs A Stewart

Senior Lecturer

Physiotherapy Department

7 York Rd PARKTOWN 2I93 
This study was undertaken to identify the health behaviour of patients attending a hypertension clinic at a primary health care centre in a depressed socio-economic area of Johannesburg, South Africa. The aim of this study was to evaluate the individual, social and environmental factors and the medical regimen which may influence patients' health behaviour and thus their health status.

\section{METHOD}

Ethical clearance for this study was obtained from the human ethics committee of the University of the Witwatersrand. A descriptive qualitative approach was used in this study.

\section{SAMPLE}

1. A "typical case" sample of patients was drawn from the chronic diseases clinic at Alexandra Health Clinic, an urban primary health clinic in a depressed socioeconomic area in Johannesburg. South Africa. Typical case sampling was used to illustrate "average" examples (Patton, 1987). This was done by examining compliance data established by the clinic and from a previous study done at the clinic. (Donahue, 1996; Eales and Stewart, 1996). Patients were included in the study if they had been identified as moderate to severe hypertensives, if they had been coming to the clinic for at least 6 months and if they were between the ages of 25-70 years.

2. A group of 17 patients was interviewed

3. All health-care practitioners involved at the clinic were interviewed, 6 in all.

4. A family member of the patients who lived with their families was sent a questionnaire via the patients, provided that the patients agreed to this. A total of 6 questionnaires was sent out.

All participants signed informed consent.

\section{DEMOGRAPHIC DATA OF PATIENTS}

The sample consisted of 17 patients, 15 were female and 2 were male. The mean age was 56 and the mean educational level was Grade 8 . Nine were unemployed, 3 worked part-time and 2 were employed full-time and three were pensioners. Fifteen lived with their families, 1 on her own and 1 in an old-age home. The mean height was $161 \mathrm{cms}$ and their mean mass was $73 \mathrm{kgs}$. Their BMI was 28.1. Their mean blood pressure level was 157/99. They had been at the clinic for a mean of 4.3 years.

\section{TABLE 1: EXAMPLES OF INTERVIEW QUESTIONS FOR PATIENTS}

- What do you think caused your illness?

- Why do you think it started when it did?

- What do you think this illness does to you?

- How does it work?

- How bad do you think your illness is?

- Do you think it will last for a long time or be better soon?

- What kind of treatment do you get at the clinic?

- What kind of treatment would you like to have?

- What do the staff at the clinic teach you about your illness?

- Do you think that what you eat affects your illness?

- Do you do any exercise?

- Do you drink or smoke?

- Do you get worried about things?

- What do you do to look after yourself?

- What are the problems your illness has caused you?

- Does your family help you?

- Can you get time off work to come to the clinic?

- Do you have to wait for a long time at the clinic?

- Is it difficult for you to get to the clinic?

An example of a probe question is: What are the things that worry you?

\section{DEMOGRAPHIC DATA OF THE HEALTH-CARE PRACTITIONERS}

The 6 health care professionals included one male physician who had been in charge of the clinic since it's inception 6 years ago, 2 female primary health care nurses who had been at the clinic for 4 years and 3 female lay health care workers who had been at the clinic for variable lengths of time

\section{Data Collection}

All participants signed informed consent prior to participation in the study.

\section{Interviews}

Patients who could speak English and the health care practitioners were interviewed by the first author. In the case of the Sotho and Zulu patients a second interviewer namely a qualified physiotherapist who was Sotho speaking and who had been trained by the researcher did the interviews. Semi-structured interviews using "open-ended" and "probe" questions covered the areas listed in Table 1 and Table 2. All interviews were tape-recorded. The patients and the health care practitioners were either given the opportunity to listen to the tape-recordings and make any changes if they wished to, or were given copies of the transcripts to check and make changes as they wished. This was done in order to establish the credibility (internal validity) of the data (Merriman, 1988). The "open-ended" questions were used in such a way as to get the maximum depth of answer from the subjects. The format of the questions was changed to get greater clarity if required and "probe" questions were used to get more information in certain areas of the interview if needed. The basic framework for the questions asked comes from Kleinman et al (1978) who proposed that such questions could be used to gain information about the patient's understanding of their disease. Tables 1 and 2 give examples of questions asked.

The patients were given a one page questionnaire to give to a family member 
TABLE 2: EXAMPLES OF QUESTIONS ASKED OF HEALTH-CARE PRACTITIONERS

\section{Disease Beliefs}

- What do patients believe is wrong with them?

- Do they understand the causes of hypertension?

- Do they understand that it is a chronic disease?

- Do they understand the complications?

\section{Treatment Beliefs}

- How good is the patients' compliance?

- What key information should the patients have?

- What do they understand about reduction of risk factors?

- How do you check up on them?

- Do they know what medication they are on and what it does?

\section{Barriers}

- What sort of things affect patients' compliance?

- What influence do their families have-are they supportive?

- Are they motivated to comply with health advice?

- Do they understand what they have to do?

- Do they forget about taking their medication?

- Do they deny that they are ill?

to fill in and send back to the researcher. A stamped return envelope was included. The questionnaire was based on the questions used in the interviews for the patients and health care practitioners.

Sufficient numbers of the above subjects were interviewed to ensure saturation of the data (Strauss and Corbin, 1990) that is the stage where no new data were being obtained.

\section{Observation}

The interactions between patients and the health-care practitioners at the clinic was observed by the first author, and observational memos written with particular reference to the therapeutic relationship between patients and practitioners, and the method of patient education.

\section{ANALYSIS OF ARTIFACTS}

The patients' records were examined to establish therapeutic regimen. Patients' records were also used to establish the compliance of patients to both the medication regime and risk factor modification.
These were examined over the six month period leading up to the study, however some of the data in the patients' files were incomplete. (Table 3).

\section{ANALYSIS OF THE DATA}

The tape recordings were transcribed "in extenso". The Sotho and Zulu interviews were transcribed and then translated into English by a translator in the African languages department at the University of the Witwatersrand. The second interviewer then checked the translations for their contextual sense. Detailed field notes were made both during and immediately after the observations at the clinic. The compliance data was condensed by using means and ranges. All the data was then analysed in the following way (Merriman, 1988; Strauss and Corbin, 1990).

\section{Step 1}

\section{Open Coding}

The transcripts were read through sufficient times to establish common concepts.
Line by line analysis was done in order to establish these concepts. The concepts were then grouped into discreet categories. Similar categories were then grouped into broader categories and these categories appropriately coded in order to reduce the data in such a way that comparisons across interviews could be made.

\section{Step 2}

\section{Axial Coding}

Axial coding was then undertaken to make connections between the categories in the open coding so that the most important themes from the data could be identified. From this the theory or relationships between categories could be established by considering causal conditions, context, interactive effects and consequences.

\section{Step 3}

\section{Reliability Check}

The categories identified in the transcribed data were checked for reliability. A researcher who was not involved in the data collection reviewed subsets of the data and independently coded the data. An interrater reliability of $85 \%$ was achieved. This process ensured that the codes/categories were understandable, exhaustive, mutually exclusive and independent.

\section{Step 4}

\section{Trustworthiness of the Data}

The trustworthiness of the data, that is the "credibility, transferability and dependability" of the data, was determined in the following manner (Strauss and Corbin, 1990; Patton, 1987; Lincoln and Guba, 1985).

1.The exact language of the interviews was analysed within meaningful segments of speech. Use of subjects' exact language is known as "thick low inference data", that is the researcher keeps inferences made about the data close to the exact words used by the subjects. An example of exact language is, "Actually you know sometimes when I wake up in the morning then I think of something like going to work you see then there is something that is exciting me. I feel very much excited then suddenly I get palpitations and the headaches then I realise oh no the blood pressure is high."

2. Triangulation of the data was achieved by looking for similarities found in multiple data sources, for example, from interviews of patients, health-care 
practitioners and family members, from interactions between patients and healthcare workers and from patients' records. Credibility of the date is ensured when the same factors, for example support or lack of support by family members, are identified from a number of different sources.

3. Member Check

Subjects listened to the tape recordings or read through the transcripts and made changes if they needed to. This ensured that the researcher accurately captured the interviewee's perspective.

4. Reliability check of data coding Subsets of data were coded and an interrater reliability of $85 \%$ was obtained.

5. Data saturation

Data were collected and analysed using multiple methods and sources until saturation of data was obtained, that is until no new concepts or categories emerged.

\section{RESULTS AND DISCUSSION}

The themes generated in this study are discussed under the patients' health behaviour, health status and the factors affecting compliance as described by Bartlett (1982).

\section{FACTORS AFFECTING COMPLIANCE}

\section{Individual Factors}

\section{Knowledge}

Studies on compliance state that in order for patients to be able to accept health advice and comply with medical instructions they need to have a basic understanding of the pathology and the nature of the disease which they are trying to manage (Heggenhougen and Shore, 1986; Stanton, 1987). They need to be able to make a connection between the health behaviours they are trying to adopt and the effect they will have on the disease process. This sample of patients had a very limited idea of the pathology of hypertension. None of them described it as being a pressure problem, or increased resistance in their blood vessels. A few of the patients felt that it had something to do with the heart or with the blood. There is a perception among the staff that some patients think that they have too much blood, which could explain why it is often referred to as "high blood", leaving off the most important word which is pressure. However although the patients talk about
TABLE 3: COMPLIANCE AND SYMPTOM DATA FROM PATIENTS' FILES

\section{The patient attendance over a 6 month period ranged from $33 \%$ to $100 \%$ with a mean of $66 \%$.}

\section{Pill count incomplete data}

\section{Compliance with life-style changes}

$\begin{array}{lll}\text { Food } \quad \text { Salt } & 4 \text { patients were using salt } \\ & \text { - Meat } & \text { Average of } 3 x \text { per week (range 2x-4x) } \\ \text { Exercise } & \text { None was exercising } \\ \text { Alcohol } & \text { One patient abused alcohol } \\ \text { Smoking } & \text { None was smoking }\end{array}$

\section{Symptoms}

$\begin{array}{ll}\text { Nocturia } & -6 \text { patients } \\ \text { Headaches } & -3 \text { patients } \\ \text { Dizzy } & -1 \text { patient } \\ \text { Palpitations } & -1 \text { patient }\end{array}$

hypertension as being "high blood", this perception among the staff was not evident in the patients' descriptions. They said that they had "high blood" but, except for one patient, did not say that they had too much blood. The staff felt that the patients did not understand what high blood pressure was.

The doctor felt that patients needed to know that it was a pressure problem and that it was a silent disease. The staff and in particular the lay health workers, when asked what they felt patients should know, concentrated on the compliance to the medical regimen and diet and did not mention an understanding of the pathology.

When asked what their blood pressure was only a few patients said that it was "170 or something" or " $150 / 90$ or something." Some said "it is high" and some could feel when their blood pressure was high because they experienced symptoms. A few of the older patients seemed to understand that hypertension was a chronic disease but in this understanding there almost seemed to be an inevitability about it, some saying that the next stage was a stroke.

With the exception of one patient, at no time did patients express any understanding of the fact that hypertension could be controlled. They did not realise that although it would be with them always, they could by their own actions lessen the impact on their lives. With the exception of the doctor, who said that the disease was silent and that control was important, none of the staff identified blood pressure control and the understanding that hypertension is a chronic disease as being facts that patients should understand. Although the doctor said that patients knew that their blood pressure should be 120/80 and that was what they were aiming at, this was not the case. All that came across in the patients' interviews was the perception that their blood pressure "must be lower".

\section{Symptoms}

When asked about their physical status patients complained about being symptomatic. They complained that they often had headaches, frequently when they woke up but also at other times of the day. They were also frequently dizzy. These symptoms interfered with their work and their ability to manage household chores. They also had a variety of ill defined aches and pains particularly the older ones. Many of them spoke about the fact that they felt as though they "were falling". This is possibly due to the dizziness. 
This picture is far from the "silent disease" often quoted in the literature and described by the doctor, who said that patients need to understand that hypertension is a silent chronic disease. However there is a perception that patients usually come to the clinic when they are symptomatic and don't attend when they are asymptomatic.

They could describe how they felt when they were feeling well. They said that they felt strong and could get out of bed and do their work. When they were not feeling well they felt weak and did not want to get up. One patient described it as, "I feel in the morning when I wake up that I don't want to have anything to do with me". Some of them said that they were aware of their hearts pumping and they had a feeling of heat at night such that they could not sleep under the blankets. They described a heaviness in their legs and that their legs were swollen like "the legs of an old woman". The symptoms described by these patients were similar to the descriptions of a group of AfricanAmerican patients in a study done in New Orleans (Heurtin-Roberts and Reisin, 1992).

The staff did not feel or record that the patients were symptomatic and the only symptoms which appeared on the flowsheet with any regularity were nocturia and sometimes headaches and dizziness. Some of the patients said that if they took their medication they felt fine. It was difficult to ascertain the linkage between compliance with medication and decrease of symptoms.

\section{Stress}

All the patients spoke about their worries and resultant stress, to the point that they were central to the patients' descriptions of their illness experiences. Worries and stress were mostly linked to financial and family problems. Many of them had had some sort of event which they felt had increased their stress, and this event was often a family problem. An example of a patient's stress is contained in the following description: "I think what disturbed me was my mother's death. She was killed by a car and that worried me. My boy was shot in 1991, he was selling beer. The other one is crazy and the last one is at home in Mabopane".

They also worried that if they did have a job that there would be problems taking time off to come to the clinic. Poor compliance is linked to disturbing life events such as general poor health, being unmar- ried, unemployed and having a lower income (Caldwell et al, 1983).

The staff did not see this as the biggest problem facing the patients although some of them mentioned work related and financial concerns as worrying the patients. The problems of family, unemployment and financial worries seemed to be the over-riding concerns of these patients.

\section{Education}

The group of patients who were interviewed in English had a mean educational level of Grade 11 (Grade 8-Grade12) and the group interviewed in Sotho or Zulu had a mean level of Grade 5 (Grade 0 to Grade 12). Generally the patients were poorly educated and those who were employed had unskilled jobs. Compliance with this level of education is always problematic (Haynes, 1976).

Most of the patients felt that they were not being educated at the clinic. This observation was borne out by the staff. The staff said that they did not have time to educate the patients because they had to deal with very long queues of patients and they were short staffed. Patients who had been at the clinic for a number of years seemed to feel that they had had some education at some stage and some said that they were given some exercises at the clinic. Staff used a "flowsheet" (which listed symptoms, signs and compliance issues) as an educational tool and as they checked the patient's signs, symptoms and compliance they explained and reinforced diet and medication compliance.

\section{SOCIAL FACTORS}

\section{Family Support}

The staff felt that the patients did not get very much family support. This was because it was not obvious that there was anything wrong with the patient. Some of the patients said that their families were worried about them but in many instances they themselves were in fact carrying the financial and other responsibilities for the families. For the most part they did not get very much help with household responsibilities nor help with the management of their medical regimen and dietary requirements. The addition of some sort of family support is an important factor in patient compliance (Bartlett, 1982; Strogartz and Earp, 1983; Hill, 1989; Whetstone and Reid, 1991).

A total of 6 questionnaires were sent home with the patients to be filled in by family members. Only one reply was re- ceived. This may further illustrate the lack of family involvement.

\section{Patient Staff Interactions}

Patients said that they felt free to ask questions of the staff and felt that the staff "were free" that is that they were friendly. However most of them did not ask questions and some did not appear to want to ask questions The staff, with the exception of the doctor, came from similar cultural backgrounds and spoke the same languages. In this way transcultural interaction difficulties were avoided (de Villiers, 1991). The observed interactions were very brief but were friendly and non threatening. The point was made that patients are continually encouraged to comply with treatment and the information is continually reinforced. Patients are not dealt with in a judgmental way but are praised and encouraged all the time. The relationship between patient and health care practitioner is a very important one in the management of chronic disease. The relationship should be one of negotiation between the patient and health care practitioner. This negotiation process affects the doctor patient relationship and in turn the medical care (Evans et al, 1987; Bothelo, 1992).

\section{Patient-Employer Relationship}

Patients who were employed expressed concerns about having to be at the clinic for such a long time on their "check-up" days. They felt that their employers had difficulty in giving them the time off work needed for them to come to the clinic.

\section{ENVIRONMENTAL FACTORS}

\section{Transport}

Most patients felt that to get to the clinic was not a problem because of the very good taxi service. The main problem in this regard was the ability to pay for the taxi. Some of them were within walking distance of the clinic. Accessibility of clinics and transport problems can add to patients' difficulties with compliance. Keeping appointments with health-care providers can involve five different activities. These are; making the appointment, arranging transport, arranging other obligations for example child care, getting time off work and making the next appointment (Hill, 1989).

\section{Financial Concerns}

Many patients expressed their concerns about financial difficulties. These concerns 
affected their daily lives. Financial restrictions also affected their ability to manage appropriate dietary recommendations. Patients lost money while they spent time at the clinic and often had difficulty paying for transport to the clinic. The staff identified financial problems as one of the difficulties the patients had to deal with. The treatment itself was free if the patients were unemployed. Financial considerations will affect patients' ability to comply with medication (Flack, 1996).

\section{Queves}

The patients arrive at the clinic in the early hours of the morning some getting there as early as $0500 \mathrm{hrs}$. They then wait in queues for attention. They can have up to a 5-6 hour wait to be seen and to collect their medications. The interaction time with various health care practitioners is approximately 10-15 minutes. The clinic has only one doctor and he is often away at meetings and involved in other administrative obligations. If patients are scheduled to see the doctor they are inevitably further delayed. The patients spend the better part of a working day at the clinic and most of them get medication to last a 4 week period, which means that patients spend a day at the clinic every month. This creates problems for patients who are employed, as they feel that employers are not always sympathetic and if they are self employed mostly as hawkers they are losing time to make money.

\section{MEDICAL REGIMEN}

The patients all knew how many drugs they were taking and mostly identified them by colour. They seemed to know when the drugs should be taken. In addition to the drugs for hypertension patients frequently took medication such as Panado and Brufen for "pains". They knew that the drugs for hypertension were to bring their blood pressure down but they did not know the effects of their individual drugs. Limited discussion of the effects of drugs took place

A pill count was done in the sense that patients were asked how many tablets they had left over and when they last took them. This was recorded on the flow sheet. Patients said that they sometimes forgot to take their pills particularly when they were working and busy with other things. The staff concurred with this observation. Patients require a combination of approaches such as reminder strategies to help them adhere to their drug regimen (Green et al, 1979). The staff were of the opinion that patients forgot their medication when they felt well, this led to poor control of hypertension resulting in the patients becoming symptomatic. The data on pill counts was difficult to use because of discrepancies in the way data were recorded (see Table 3).

\section{PATIENTS' HEALTH BEHAVIOUR}

\section{Disease management}

Central to this clinic for chronic diseases is the thought that patients should comply in order for the management of hypertension to be effective. The doctor stated that this was the most important consideration of the clinic. The health workers all explained how they taught patients what to eat. They must not eat salt, they must eat vegetables, must cut down on red meat and tinned foods and replace them with chicken. One mentioned sugar as being unacceptable. The "flowsheet" used by the staff listed the foods that patients should and should not eat and this was used to check patients' compliance. Patients knew that they should cut down on meat, tinned food and salt. This information appeared to be well understood by patients. They said that they tried to eat the "right things". Difficulties were experienced when they did not do the cooking and they were dependent on others for the preparation of their meals. Another problem was financial which made the acquisition of the right foods a problem. The staff also felt that the patients tried to comply. This education of patients as to what they should eat seemed to pervade everything. Staff were of the opinion that this is primarily what they taught and this was exactly the knowledge patients had gained from them. The nature of the flowsheet was such that what patients had been eating was checked on at each visit to the clinic.

There was only one member of the staff who mentioned the importance of weight control. Only one patient mentioned the need to control her weight. The link between the correct diet and weight loss had not been identified by the health care workers and therefore was not perceived by the patients. This was similar to the New Orleans study (Heurtin-Roberts and Reisin, 1996). Patients spoke about what they should eat but did not say that they needed to keep their weight within certain limits. This was despite all the patients being weighed at each attendance at the clinic.

\section{Attendance at the Clinic}

Over a period of six months the attendance of a patient was on average $66 \%$. It was not possible to judge the medication compliance from the patients' records. Most of the patients said that they took their medication regularly although some admitted that they forgot at times. Studies at the clinic have shown blood pressure control to be poor (Donovan, 1996; Eales and Stewart, 1996). Blood pressure only starts to fall significantly when patients take $89 \%$ of their medication. The adherence to the medical regimen is the single most difficult problem in the management of essential hypertension (Morisky et al, 1986; Hill, 1989). Poor blood pressure control is associated with poor compliance (Caldwell et al, 1983).

\section{Drinking and Smoking}

The sample did not smoke and did not drink very much with the exception of one patient who abused alcohol. The patients did not mention either of these two risk factors as needing to be controlled. They also did not see either drinking or smoking as causes of hypertension. Only the doctor and one other member of the staff, when asked what patients needed to know, mentioned drinking and smoking as risk factors which the patients needed to modify.

\section{HEALTH STATUS}

The mean blood pressure level of this sample of patients was $157 / 99$ which does not reflect effective blood pressure control. In addition they were often symptomatic, complaining of frequent headaches and dizziness.

\section{CONCLUSION}

The blood pressure control of these patients is poor, as is the patients' compliance. Their understanding of the disease is fragmented thus making it difficult for them to really know what it is that they are trying to achieve. The concept of a silent chronic disease requiring control did not come across at all. Patients felt symptomatic often. They were beset by worries and stresses due to financial concerns and family problems. The staff emphasized eating the correct food and patients were very aware of what they should be eating but not that weight control was important. Therefore what the staff felt was important to teach patients, they had successfully taught. If the staff were more aware of the essential knowledge required to control hypertension, it 
seems reasonable that patients would successfully comply with the total regimen to control hypertension.

The staff felt that they had too many patients to deal with and as a result the education of the patients had been compromised. However it would seem that the ability to teach is not the problem but the content that must be taught is lacking.

The above conclusions can be presented in a new framework as follows:

(see Figure 2)

\section{ACKNOWLEDGEMENT}

The authors would like to thank the patients and staff at the Alexandra Health Clinic for their help in making this study possible.

\section{FIGURE 2: FACTORS RELATED TO POOR COMPLIANCE BY BLACK HYPERTENSIVE PATIENTS IN A DEPRESSED SOCIO-ECONOMIC AREA OF SOUTH AFRICA}

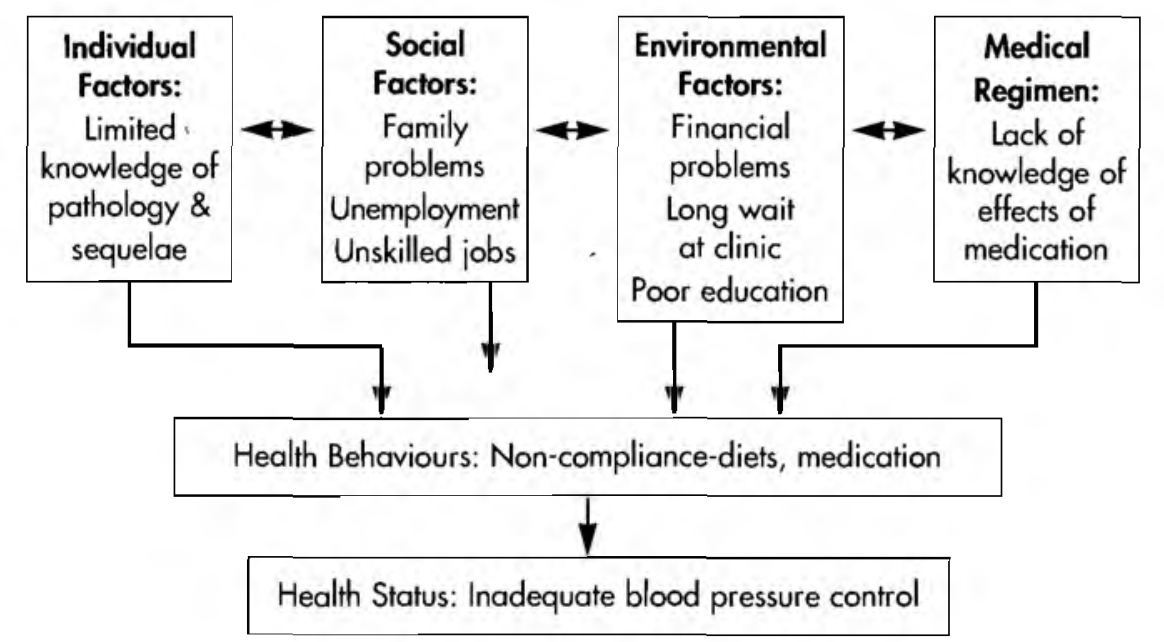

\section{REFERENCES}

Bartlett E E 1982 Behavioural diagnosis: a practical approach to patient education. Patient Counselling and Health Education 4: 29-35

Bothelo R J 1992 A negotiation model for the doctor-patient relationship. Family Practitioner 9(2): $210-218$

Caldwell J R, Theisen V, Kaunisto C A Reddy P J, Smythe P S, Smith D W 1983 Psychosocial factors influence control of moderate and severe hypertension. Social Science and Medicine 17(12): 773-782

de Villiers S 1991 Beliefs and behaviours in transcultural health-care. South African Family Practioner: 44-49

Donohue S 1996 A description and evaluation of the chronic disease clinic at Alexandra health clinic. Unpublished Report

Eales C J, Stewart A V 1996 The exercise capacity of three socio-economic groups of hypertensive patients. Phys Res Int 1(4): 255 264

Evans B J, Kiellerup F D, Stanley R O, Burrows G D, Sweet B 1987 A communication skills programme for increasing patients' satisfaction with general practice consultations. British Journal of Med Psych 60: 373 378

Flack J M, Novikov S V, Ferrario C M 1996 Benefits of adherence to anti-hypertensive drug therapy. European Heart Journal 17 (suppA): $16-20$

Green L W 1978 Determining the impact and effectiveness of health education as it relates to federal policy. Health Ed Monogr 6 (supl): 28-66
Green L W, Levine D M, Wolle R 1979 Development of randomised patient education experiments with urban hypertensives. Pt Educ and Counsel 106-111

Haynes R B 1976 Improvement of medication compliance in uncontrolled hypertension. Lancet 1: 1265-1268

Heggenhougen H K and Shore L 1986 Cultural components of behavioural epidemiology: implications for primary health care. Social Science and Medicine 22(11): 1235-1245

Heurtin-Roberts S, Reisin E 1992 The relation of culturally influenced models of hypertension to compliance with treatment. American Journal of Hypertension 5(11): 787-792

Hill M N 1989 Strategies for patient education. Clin and Exper Hyperten and Prac A 11 $(5,6): 1187-1201$

Janz N K and Becker M H 1984 The health belief model: a decade later Health Educ Quat 11:11-47

Jenkins C D 1979 An approach to the diagnosis and treatment of problems of health-related behaviour. International Journal of Health Education 22(Supp 1): 1-24

Kleinman A, Eisenberg L and Good B 1978 Culture, illness and care: clinical lessons from anthropologic and cross-cultural research Annals of Internal Medicine 88: 251-258

Lincoln Y, Guba E 1985 Naturalistic Inquiry. Sage Pub CA

Merriman S B 1988 Case study research in education a qualitative approach. Jossey Bass Pub San Francisco and London
Morisky D E, Bowler M H, Finlay J S 1982 An educational and behavioural approach toward increasing patient activation in hypertension management. J of Com Health 7(3): 17I-181

Morisky D E, Green L W, Levine D M 1986 Concurrent and predictive validity of a selfreported measure of medication adherence. Medical Care 24(1): 67-74

Morisky D E, Levine D M, Green L W, Shapiro S, Patterson Russel R, Smith C R 1983 Five-year blood pressure control and mortality following health education for hypertensive patients. AJPH 73(2): 153-162

Patton M Q 1987 How to use qualitative methods in evaluation. Sage Pub C A

Sluijs E M, Knibbe J J 199 I Patient compliance with exercise: different theoretical approaches to short term and long term compliance. Patient Education and Counselling 17: 191-204

Stanton A L 1987 Determinants of adherence to medical regimens by hypertensive patients. Journal of Behaviour Medicine 10(4): 377-394

Strauss A, Corbin J 1990 Basics of qualitative research. Sage Pub Inc Newbury Park Cal

Strogartz D S, Earp J L 1983 The determinants of dropping out of care among hypertensive patients receiving a behavioural intervention. Medical Care 21(10): 970-980

Whetstone W R, Reid J C 1991 Health promotion of older adults: perceived barriers. J of Adv Nurs 16: 1343-1349 